\title{
3 Research Square

\section{Use of the PALLIA 10 Score in Patients Enrolled in Phase I Trials at Gustave Roussy Cancer Center}

Kaïssa Ouali ( $\square$ kaissa.ouali@gustaveroussy.fr )

Institut Gustave Roussy https://orcid.org/0000-0002-8269-3001

\section{Cristine Mateus}

Institut Gustave Roussy: Gustave Roussy

Arianne Laparra

Institut Gustave-Roussy: Gustave Roussy

Elena Pavliuc

Institut Gustave-Roussy: Gustave Roussy

Patricia Martin-Romano

Institut Gustave Roussy: Gustave Roussy

Anda Sampetrean

Institut Gustave Roussy: Gustave Roussy

Perrine Vuagnat

Institut Gustave Roussy: Gustave Roussy

Andrea Varga

Institut Gustave Roussy: Gustave Roussy

Stephane Champiat

Institut Gustave-Roussy: Gustave Roussy

Loic Verlingue

Institute Gustave-Roussy: Gustave Roussy

Arthur Geraud

Institut Gustave Roussy: Gustave Roussy

Aurelien Marabelle

Institut Gustave Roussy: Gustave Roussy

Antoine Hollebecque

Institut Gustave Roussy: Gustave Roussy

Anas Gazzah

Institut Gustave Roussy: Gustave Roussy

Rastilav Bahleda

Institut Gustave Roussy: Gustave Roussy

Sophie Postel Vinay

Institut Gustave Roussy: Gustave Roussy

Jean-marie Michot 
Institut Gustave Roussy: Gustave Roussy

\section{Alice Bernard-Tessier}

Institut Gustave Roussy: Gustave Roussy

\section{Arnaud Bayle}

Institut Gustave Roussy: Gustave Roussy

\section{Vincent Ribrag}

Institut Gustave Roussy: Gustave Roussy

\section{Jean-Charles Soria}

Institut Gustave Roussy: Gustave Roussy

\section{Florian Scotte}

Institut Gustave Roussy: Gustave Roussy

\section{Christophe Massard}

Institut Gustave Roussy: Gustave Roussy

\section{Capucine Baldini}

Institut Gustave Roussy: Gustave Roussy

\section{Research Article}

Keywords: early palliative care, supportive care, phase I trials, PALLIA 10

Posted Date: January 3rd, 2022

DOl: https://doi.org/10.21203/rs.3.rs-1141116/v1

License: (c) (1) This work is licensed under a Creative Commons Attribution 4.0 International License. Read Full License

Version of Record: A version of this preprint was published at Journal of Clinical Oncology on October 1st, 2021. See the published version at https://doi.org/10.1200/JC0.2020.39.28_suppl.23. 


\section{Abstract \\ Background}

Early phase clinical trials usually include patients with advanced disease who have failed standard therapies. Early palliative care for these patients has shown to improve quality of life and even survival. PALLIA 10 score (ranging from 1 to 10) is a tool developed by the French Palliative Care Society to identify the best time to introduce palliative care.

\section{Methods}

We assessed the PALLIA 10 score and other prognostic factors (age, ECOG, Royal Marsden Hospital $(\mathrm{RMH})$ score, LDH and albumin levels, number of prior systemic treatments and metastatic sites) in patients enrolled in phase I trials at Gustave Roussy Cancer Center prospectively during 2 periods of time (cohort 1 (C1) and 2 (C2)). A double-blind assessment of the PALLIA 10 score was done during 15 days by a member of the palliative care unit in C2. A PALLIA $10>3$ motivated a dedicated palliative care consultation.

\section{Results}

From July 1st 2018 to November 1st 2018 (C1) and from December 1st 2020 to April 16th 2021 (C2), a total of 86 patients were assessed in $\mathrm{C} 1$ and 302 in C2. No difference was observed between the two cohorts regarding prognostic factors. Median PALLIA 10 was also similar and very low (median 1, range 1-5 in $\mathrm{C} 1$ and $1-8$ in $\mathrm{C} 2$ ). On $\mathrm{C} 1$ and $\mathrm{C} 2,12 \%$ and $5 \%$ of patients had a dedicated palliative consultation. Overall, $77 \%$ and $74 \%$ of patients in $\mathrm{C} 1$ and $\mathrm{C} 2$ were still alive beyond 3 months after discontinuation of the trial $(p=0.78)$, followed by at least one subsequent treatment in $63 \%$ and $70 \%$ of pts. In $\mathrm{C} 2$, assessment of PALLIA 10 score was significantly different between palliative care physician (median 5 , range $3-8$ ), phase I physician (median 1 , range $1-6)$ and phase I nurse (median 3 , range $1-8)(p<0.001$ ).

\section{Conclusion}

Only a few patients included in phase I clinical trial were referred to the palliative care unit. Median PALLIA 10 score was low when assessed by the phase I physician which suggests the need for a better tool to implement early palliative care in clinical practice and trials.

\section{Introduction}

Multiples studies have demonstrated that early palliative care enhances quality of life with fewer refractory symptoms but also improved survival in patients with advanced cancer(1-4), leading to the integration of supportive and palliative care as a pillar in the guidelines of several oncology organizations 
such as the American Society of Clinical Oncology (ASCO) (5) or the European Society of Medical Oncology (ESMO) (6) for the management of cancer patients with advanced disease.

Diverse clinical and biological markers can be used as prognostic and predictive factors for cancer patients(7-9). However, there is currently no validated tool to help clinicians to identify the patients who might benefit from a palliative care consultation and determine the best time to refer them. The French palliative care society (SFAP) tried in this context to create a tool, named PALLIA 10, a score composed of ten questions, evaluating multiples aspects of the patient's daily life, ranging from the presence of physical or psychological refractory symptoms to the evolution and the comprehension of the stage of the disease. The questionnaire is intended for patients who cannot be cured; a positive reply to each item leads to an extra point, leading to a score ranging from 1 to 10 (Supplementary Data). An assessment by the palliative care team is considered required if the score is $>3$. PREPA 10, a multicenter study performed in 18 cancer centers in France, has concluded that the PALLIA 10 score might be a prognostic and predictive factor of death within 6 months if it was superior at $3(10)$.

Phase I trials are usually known to recruit patients with advanced disease who have failed standard therapy and thus might benefit from early palliative care $(11,12)$. Although there has been an improvement in objective response rate in phase I trials between the early 2000's and now, from 10 (13) to nearly $20 \%$ (14), the clinical benefit might still not be enough for those patients. We aimed to evaluate if PALLIA 10 could be used in our phase I department at Gustave Roussy Cancer Center in order to address patients who will benefit from a palliative care follow-up.

\section{Material And Methods}

\section{Patients}

We included prospectively patients included in early clinical trials in our institution during two-time ranges in 2018 and in 2020/21. In the 2018 cohort (C1), only patients who were beginning the trial during our period of analysis were included, while in the 2020/21 (C2) patients who were already on treatment were also evaluated. PALLIA 10 score was realized by a phase I physician for all the patients included in both cohorts. We reported different other prognostic factors for each patient from their medical records: age, ECOG, LDH (lactate deshydrogenase) and albumin levels, number of prior systemic treatments and metastatic sites. Royal Marsden Hospital (RMH score), a validated phase I prognostic score, composed of 3 of these items (LDH and albumin levels and number of metastatic sites) was also evaluated (15).

Overall survival was assessed as well as subsequent lines of treatment after discontinuation of the trial. The aim of using two cohorts was to see if there was any changes in terms of prognostic factors in the 2year period for patients included in phase I trial and to assess whether the fact that different physicians were assessing the patients led to differences in PALLIA10 score.

\section{Palliative care referral}


We evaluated if patients were referred to a palliative care team during their follow-up and the time between the beginning of the trial and the first palliative care evaluation.

\section{Double blind study}

In the second cohort, we realized a double-blind assessment of PALLIA 10 score by a phase I physician and a palliative care specialist during a first 15-days period. We then repeated this practice in a second 15-days period within $\mathrm{C} 2$ adding a phase I nurse evaluation.

\section{Statistics}

Descriptive statistics were used to describe patient characteristics. Comparison between the two cohorts were done using a chi-2 test, overall survival was evaluated with a Log Rank test. Statistics were made using GraphPad Prism 9.

\section{Objectives}

The primary objective was to assess if the PALLIA 10 score could be used in our phase I department as a tool to select patients who will benefit from a palliative care referral. The secondary objective was to find out whether the patients evolved over the 2-year period in terms of clinical profil and prognostic factors.

\section{Results}

\section{Patient characteristics}

During the 2018 cohort (C1), a total of 86 patients were included in our study from July 1 st 2018 to November 1st 2018, while 302 were evaluated in C2 between December 1st 2020 and April 16th 2021. Gastro-intestinal (23\%), hematological (14\%), genito-urinary (12\%) and lung (11\%) cancers were the most frequent tumor types. As expected in early clinical trial, most patients had an ECOG of 0 or 1 and had already received $\geq 3$ lines of therapy (Table 1). Two patients in $\mathrm{C} 1$ and one in $\mathrm{C} 2$ already had seen the palliative care team before beginning the trial. 
Table 1

Patient characteristics on cohort 12018 (C1) and cohort 2 2020/21 (C2)

\begin{tabular}{|c|c|c|}
\hline & $\begin{array}{l}\text { Cohort } 1(C 1) \\
n=86(\%)\end{array}$ & $\begin{array}{l}\text { Cohort } 2 \text { (C2) } \\
n=302(\%)\end{array}$ \\
\hline \multicolumn{3}{|l|}{ Age } \\
\hline$<50$ years old & $25(29 \%)$ & $58(19 \%)$ \\
\hline 50-70 years old & $44(51 \%)$ & 187 (62\%) \\
\hline >70 years old & $17(20 \%)$ & 57 (19\%) \\
\hline \multicolumn{3}{|l|}{ Primary cancer } \\
\hline Gastro-intestinal & $14(16 \%)$ & $74(25 \%)$ \\
\hline Hematological & $16(19 \%)$ & $36(12 \%)$ \\
\hline Lung & $8(9 \%)$ & $34(11 \%)$ \\
\hline Genito-urinary & $11(13 \%)$ & $36(12 \%)$ \\
\hline Skin & $9(11 \%)$ & $23(7.5 \%)$ \\
\hline Sarcoma & $3(3 \%)$ & $25(8 \%)$ \\
\hline ENT & $4(4 \%)$ & $23(7.5 \%)$ \\
\hline Gynecologic & $8(9 \%)$ & $14(5 \%)$ \\
\hline Breast & $4(4 \%)$ & $8(2 \%)$ \\
\hline Other & $9(11 \%)$ & $29(10 \%)$ \\
\hline \multicolumn{3}{|l|}{ ECOG PS } \\
\hline 0 & $35(41 \%)$ & $133(44 \%)$ \\
\hline 1 & $48(56 \%)$ & 157 (52\%) \\
\hline 2 & $3(3 \%)$ & $12(4 \%)$ \\
\hline \multicolumn{3}{|c|}{ Number of prior lines } \\
\hline$<3$ & $29(34 \%)$ & $93(31 \%)$ \\
\hline $3-5$ & $52(60 \%)$ & $166(55 \%)$ \\
\hline$>5$ & $5(6 \%)$ & $43(14 \%)$ \\
\hline
\end{tabular}

C1: cohort 1 (2018), C2: cohort 2 (2020/21), PS: performans status, ENT: ear, nose, troat (head and neck cancers) 


\begin{tabular}{|lll|}
\hline & $\begin{array}{c}\text { Cohort 1 (C1) } \\
\mathbf{n = 8 6}(\%)\end{array}$ & $\begin{array}{c}\text { Cohort 2 (C2) } \\
\mathbf{n}=302(\%)\end{array}$ \\
\hline Number of metastatic sites & $55(64 \%)$ & $127(42 \%)$ \\
1 & $17(20 \%)$ & $105(35 \%)$ \\
2 & $14(16 \%)$ & $70(23 \%)$ \\
\hline $\begin{array}{l}\text { C1: cohort 1 (2018), C2: cohort 2 (2020/21), PS: performans status, ENT: ear, nose, troat (head and } \\
\text { neck cancers) }\end{array}$ & \\
\hline
\end{tabular}

Regarding prognostic factors, there was no significant difference between the two cohorts in terms of age $(p=0.36)$, ECOG performance status (PS) $(p=0.85)$, number of prior lines of treatment $(p=0.14)$, LDH level $(p=0.37)$ and RMH score $(p=0.53)$, whereas there were variations observed in terms of median albumin level (40 and $44 \mathrm{~g} / \mathrm{L}, \mathrm{p}<0.001)$ and number of metastatic site $(1[0-4]$ and $2[0-5], p<0.001)$ between patients in $\mathrm{C} 1$ and $\mathrm{C} 2$ respectively (Table 2).

\section{Table 2}

Prognostic factors and PALLIA 10 assessment in cohort 1 (C1) and 2 (C2)

\begin{tabular}{|llll|}
\hline & $\begin{array}{l}\text { Cohort 1 (C1), median } \\
\text { (range) } \\
\mathrm{n}=86\end{array}$ & $\begin{array}{l}\text { Cohort 2 (C2), median } \\
\text { (range) } \\
\mathrm{n}=302\end{array}$ & $\mathrm{p}$ \\
\hline Age & $61(28-83)$ & $60(19-93)$ & 0.36 \\
\hline Prior lines of therapy & $3(1-9)$ & $3(0-20)$ & 0.14 \\
\hline Pallia 10 & $1(1-5)$ & $1(1-8)$ & 0.06 \\
\hline ECOG & $1(0-2)$ & $1(0-2)$ & 0.85 \\
\hline RMH score & $1(0-3)$ & $1(0-3)$ & 0.53 \\
\hline LDH level & $197(106-1318)$ & $224(102-2644)$ & 0.37 \\
\hline Albumin level & $40(30-48)$ & $44(29-52)$ & $<0.001$ \\
\hline $\begin{array}{l}\text { Number of metastatic } \\
\text { sites }\end{array}$ & $1(0-4)$ & $2(0-5)$ & $<0.001$ \\
\hline
\end{tabular}

\section{Pallia 10 assessment}


Median time to PALLIA 10 assessment from time to trial onset was 15.5 days [0-1874] in C2 while it was only done on the first day of treatment in C1. Median PALLIA 10 score was of 1 in the two cohorts (range in $\mathrm{C} 1$ : $1-5$ and $1-8$ in $\mathrm{C} 2, \mathrm{p}=0.06$ ). On $\mathrm{C} 1$ and $\mathrm{C} 2,12 \%$ and $5 \%$ of patients had a dedicated palliative consultation respectively $(p=0.024)$ with a median time of referral of 18 and 2 months after the trial onset $(p=0.055)$ and a median PALLIA 10 score of 1.5 and $2(p=0.65)$, respectively.

\section{Outcomes}

Overall, at data cut-off (August 1st 2021), 94\% (C1) and 60\% (C2) of the patients had progressive disease and stepped out of the trial. Among those, $77 \%$ and $74 \%$ were still alive 3 months after discontinuation of the study ( $p=0.78$ ) (Figure 1) and $63 \%$ and $70 \%$ had at least one subsequent line of treatment in $C 1$ and C2.

Median OS was 10 months in $\mathrm{C} 1$ and not reached in $\mathrm{C} 2$.

\section{Double blind Pallia 10 assessment}

The first double blind study done within C2 between November 1st 2021 and January 22nd 2021 involved the evaluation of 25 patients and showed that PALLIA 10 score what significantly higher when done by a palliative care specialist than by the phase I physician (median score of 1 and $4, p<0.001$ ). Likewise, the assessment of the score from April 12th 2021 to April 23rd 2021 for 37 patients demonstrated a higher median PALLIA 10 when it was realized by a palliative care physician than by a phase I nurse and a phase I physician (median score of 5, 3 and 1, p<0.001) (Figure 2). There was no correlation between a score $>3$ and survival at three months whether it was performed by a phase I physician $(p=0.09)$, a phase I nurse $(\mathrm{p}=0.16)$ or a palliative care physician $(\mathrm{p}=0.39)$.

\section{Discussion}

Our study showed that the use of the PALLIA 10 score in an early clinical trial department might not be as suitable as it is to help address patients to a palliative care consultation.

In our study, PALLIA 10 score was very low, with a median score of 1 in both cohorts when it was done by a phase I physician, while it was slightly higher when assessed by a phase I nurse or a palliative care specialist. Several studies have shown that it is a challenge for oncologists to call upon a palliative care team for their patients. A national American study involving 4 focus groups of medical oncologists deduced that while oncologists know and value the concept of early palliative care they were afraid that palliative care teams might interfere with the plan of care, mainly to propose to stop active treatments despite the opinion of the oncologist (16). A systematic review of 23 studies on the subject also concluded that the main reason for oncologists not wanting to refer their patients to a palliative care team was to stay in control of the treatment plan, but also the fear of rupture of the therapeutic alliance 
and creating a loss of hope for the patients. The lack of referral criteria and the limited number of palliative care specialist were also additional arguments (17). One could therefore think that one of the reasons for the low scores in our study was the fear of palliative care intervention, for instance by trying to discontinue the patient's trial. However, a study evaluating changes in quality of life for patients in phase I or II trials showed no difference in terms of number of cycles of treatments achieved in the arm receiving standard of care and the one integrating a palliative care program. Likewise, their research didn't affect the patient's and the physician's relationship (18). Another research done in California evaluating the incorporation of palliative care for 14 patients undergoing early clinical trials demonstrated the feasibility of palliative care intervention in this background, resulting in a sustainability of syndrome distress in a 3 months period of time (19). Patients also often have a flawed vision of palliative care assimilating it to end of life care only. A randomized control trial of early palliative care or standard of care conducted on patients with advanced cancers demonstrated that initially most of the patients equated palliative care to death or anxiety, but patients in the intervention arm changed their view on the subject during the trial connecting it to a better quality of life, which emphasizes the need to better educate the patients and promote palliative care (20). Furthermore, patients might put a lot of hope in phase I trial and be afraid to highlight symptoms to phase I physicians and have to discontinue the protocol. A report on 69 patients in phase I trials and 297 included in phase II or III trials deduced that patients in early clinical trials had a higher symptom burden but were less likely to seek for care services(12).

There was no difference observed in the two cohorts of patients regarding standard prognostic factors. While a difference was observed relating to albumin levels, it might be explained by a change in dosage in our local laboratory between the two assessments. There was also no difference in PALLIA10 evaluation between 2018 and 2020/21 while the physicians conducting the assessments had changed during the two-year period, which emphasizes the fact that a palliative evaluation does not depend on individuals but rather on professions' groups as mentioned above, and suggest the need to educate in particular phase I physician in palliative care. In our study, we did not find a correlation between a score $>3$ and overall survival, in contrast to the original study in which pallia 10 was a prognostic factor for survival. This difference may be due to a too short follow-up in C2, but also to the fact that the PALLIA 10 in the original study was performed by palliative care physicians and not by oncologists (10). Finally, $23 \%$ and $26 \%$ of the patients in $\mathrm{C} 1$ and $\mathrm{C} 2$ died 3 months after discontinuation of the study but only few were addressed to our palliative care team which highlight the need for a better evaluation of the patients. While our study didn't report any data regarding change in quality of life, a randomized control trial on 68 patients included in early clinical trials showed fewer adverse events and better quality of life for patients receiving palliative care than those in the control group (21).

Nurse's evaluation of the PALLIA 10 score was better than that of the phase 1 physician in our study which is concordant with what we expected. As they usually spend more time with the patients than the clinicians their interaction with the patients allows them a better grasp on patients' symptoms and perceptions. An evaluation of patients' reported adverse event using the National Cancer InstituteCommon Terminology Criteria for Adverse Event (NCl-CTCAE) showed that the nurses' assessments were 
more relevant to the patients' that those of the clinicians, especially regarding asthenia, constipation, neuropathy, mucositis and diarrhea (22). The same conclusion was drown from another report also using CTCAE that highlights a difference in symptoms' grading between physicians and patients when it comes to subjective symptoms such as fatigue or dyspnea (23). Both those studies also emphasize the possibility to revise caregiver questionnaires in order to make them comprehensible to the patient's which allows us to have the most accurate evaluation possible. In the current time, with the development of multiples digital tool in oncology, the use of patients-reported outcome (PRO) might seem to be a great alternative to caregiver's evaluation to better assess the patients' symptoms and understanding of its cancer and ultimately to allow the selection of those who need early palliative care. Currently, only few studies evaluated the incorporation of PRO in a phase I setting but with promising $(24,25)$. Larger studies on the subject are essential to improve our patients' care.

\section{Conclusion}

Only few patients were addressed to the palliative care team within the two period of time. Median PALLIA 10 was systematically low when assessed by the phase I physician even for the patients who were seen by a palliative care specialist. There was no significant change in other prognostic factors in the 3 years-period between the two cohorts. The development of an appropriate score to enable patient self-assessment using PRO could be a solution to better understand and select patients for palliative care support.

\section{Declarations}

Funding

None

\section{Conflicts of interest/Competing interests}

None

\section{Availability of data and material}

Yes

\section{Code availability}

Not applicable 


\section{Authors' contributions}

\section{Ethics approval}

Not applicable

\section{Consent to participate}

Each patients consented to participate in this study and was asked if they would agree for us to ask them questions as part of our evaluation

\section{Consent for publication}

Each patients accepted the Gustave Roussy Cancer center charter that ask them is they agree that electronical data be used for research and published

\section{References}

1. Vanbutsele G, Pardon K, Van Belle S, Surmont V, De Laat M, Colman R, et al. Effect of early and systematic integration of palliative care in patients with advanced cancer: a randomised controlled trial. Lancet Oncol. mars 2018;19(3):394-404.

2. Wright AA, Zhang B, Ray A, Mack JW, Trice E, Balboni T, et al. Associations between end-of-life discussions, patient mental health, medical care near death, and caregiver bereavement adjustment. JAMA. 8 oct 2008;300(14):1665-73.

3. Zimmermann C, Swami N, Krzyzanowska M, Hannon B, Leighl N, Oza A, et al. Early palliative care for patients with advanced cancer: a cluster-randomised controlled trial. Lancet Lond Engl. 17 mai 2014;383(9930):1721-30.

4. Temel JS, Greer JA, Muzikansky A, Gallagher ER, Admane S, Jackson VA, et al. Early palliative care for patients with metastatic non-small-cell lung cancer. N Engl J Med. 19 août 2010;363(8):733-42.

5. Ferrell BR, Temel JS, Temin S, Alesi ER, Balboni TA, Basch EM, et al. Integration of Palliative Care Into Standard Oncology Care: American Society of Clinical Oncology Clinical Practice Guideline Update. J Clin Oncol Off J Am Soc Clin Oncol. janv 2017;35(1):96-112.

6. Schrijvers D, Cherny NI, ESMO Guidelines Working Group. ESMO Clinical Practice Guidelines on palliative care: advanced care planning. Ann Oncol Off J Eur Soc Med Oncol. sept 2014;25 Suppl 3:iii138-142.

7. Hui D, Meng Y-C, Bruera S, Geng Y, Hutchins R, Mori M, et al. Referral Criteria for Outpatient Palliative Cancer Care: A Systematic Review. The Oncologist. juill 2016;21(7):895-901. 
8. Hui D, Anderson L, Tang M, Park M, Liu D, Bruera E. Examination of referral criteria for outpatient palliative care among patients with advanced cancer. Support Care Cancer Off J Multinatl Assoc Support Care Cancer. janv 2020;28(1):295-301.

9. Wadhwa D, Popovic G, Pope A, Swami N, Le LW, Zimmermann C. Factors Associated with Early Referral to Palliative Care in Outpatients with Advanced Cancer. J Palliat Med. sept 2018;21(9):1322-8.

10. Molin Y, Gallay C, Gautier J, Lardy-Cleaud A, Mayet R, Grach M-C, et al. PALLIA-10, a screening tool to identify patients needing palliative care referral in comprehensive cancer centers: A prospective multicentric study (PREPA-10). Cancer Med. juin 2019;8(6):2950-61.

11. Ploquin A, Olmos D, Ferté C, Cassier PA, Kramar A, Duhamel A, et al. Life-expectancy of patients enrolled in phase 1 clinical trials: a systematic review of published prognostic models. Crit Rev Oncol Hematol. août 2012;83(2):242-8.

12. Finlay E, Lu HL, Henderson HR, Henderson H, O'Dwyer PJ, Casarett DJ. Do phase 1 patients have greater needs for palliative care compared with other cancer patients? Cancer. 15 janv 2009;115(2):446-53.

13. Arkenau H-T, Olmos D, Ang JE, de Bono J, Judson I, Kaye S. Clinical outcome and prognostic factors for patients treated within the context of a phase I study: the Royal Marsden Hospital experience. $\mathrm{Br}$ J Cancer. 25 mars 2008;98(6):1029-33.

14. Italiano A. Trends in Modern Phase 1 Oncology Trials. N Engl J Med. 20 sept 2018;379(12):1189.

15. Garrido-Laguna I, Janku F, Vaklavas C, Falchook GS, Fu S, Hong DS, et al. Validation of the Royal Marsden Hospital prognostic score in patients treated in the Phase I Clinical Trials Program at the MD Anderson Cancer Center. Cancer. 1 mars 2012;118(5):1422-8.

16. Kruser TJ, Kruser JM, Gross JP, Moran M, Kaiser K, Szmuilowicz E, et al. Medical oncologist perspectives on palliative care reveal physician-centered barriers to early integration. Ann Palliat Med. sept 2020;9(5):2800-8.

17. Salins N, Ghoshal A, Hughes S, Preston N. How views of oncologists and haematologists impacts palliative care referral: a systematic review. BMC Palliat Care. 23 nov 2020;19(1):175.

18. Meyers FJ, Linder J, Beckett L, Christensen S, Blais J, Gandara DR. Simultaneous care: a model approach to the perceived conflict between investigational therapy and palliative care. J Pain Symptom Manage. déc 2004;28(6):548-56.

19. Sun V, Cooke L, Chung V, Uman G, Smith TJ, Ferrell B. Feasibility of a palliative care intervention for cancer patients in Phase I clinical trials. J Palliat Med. déc 2014;17(12):1365-8.

20. Zimmermann C, Swami N, Krzyzanowska M, Leighl N, Rydall A, Rodin G, et al. Perceptions of palliative care among patients with advanced cancer and their caregivers. CMAJ Can Med Assoc $\mathrm{J} J$ Assoc Medicale Can. 12 juill 2016;188(10):E217-27.

21. Treasure M, Daly B, Cao S, Fu P, Hong A, Weinstein E, et al. A randomized controlled trial of structured palliative care versus standard supportive care for patients enrolled in phase 1 clinical trials. Cancer Med. juill 2021;10(13):4312-21. 
22. Cirillo M, Venturini M, Ciccarelli L, Coati F, Bortolami O, Verlato G. Clinician versus nurse symptom reporting using the National Cancer Institute-Common Terminology Criteria for Adverse Events during chemotherapy: results of a comparison based on patient's self-reported questionnaire. Ann Oncol Off J Eur Soc Med Oncol. déc 2009;20(12):1929-35.

23. Basch E, lasonos A, McDonough T, Barz A, Culkin A, Kris MG, et al. Patient versus clinician symptom reporting using the National Cancer Institute Common Terminology Criteria for Adverse Events: results of a questionnaire-based study. Lancet Oncol. nov 2006;7(11):903-9.

24. Henon C, Lissa D, Paoletti X, Thibault C, Le Tourneau C, Lanoy E, et al. Patient-reported tolerability of adverse events in phase 1 trials. ESMO Open. 2017;2(2):e000148.

25. Sedhom R, Ferrell B, Ruel N, Koczywas M, Chung V, Smith TJ. Using Patient-Reported Outcomes to Describe the Patient Experience on Phase I Clinical Trials. JNCI Cancer Spectr. déc 2020;4(6):pkaa067.

\section{Figures}

\section{Overall Survival}

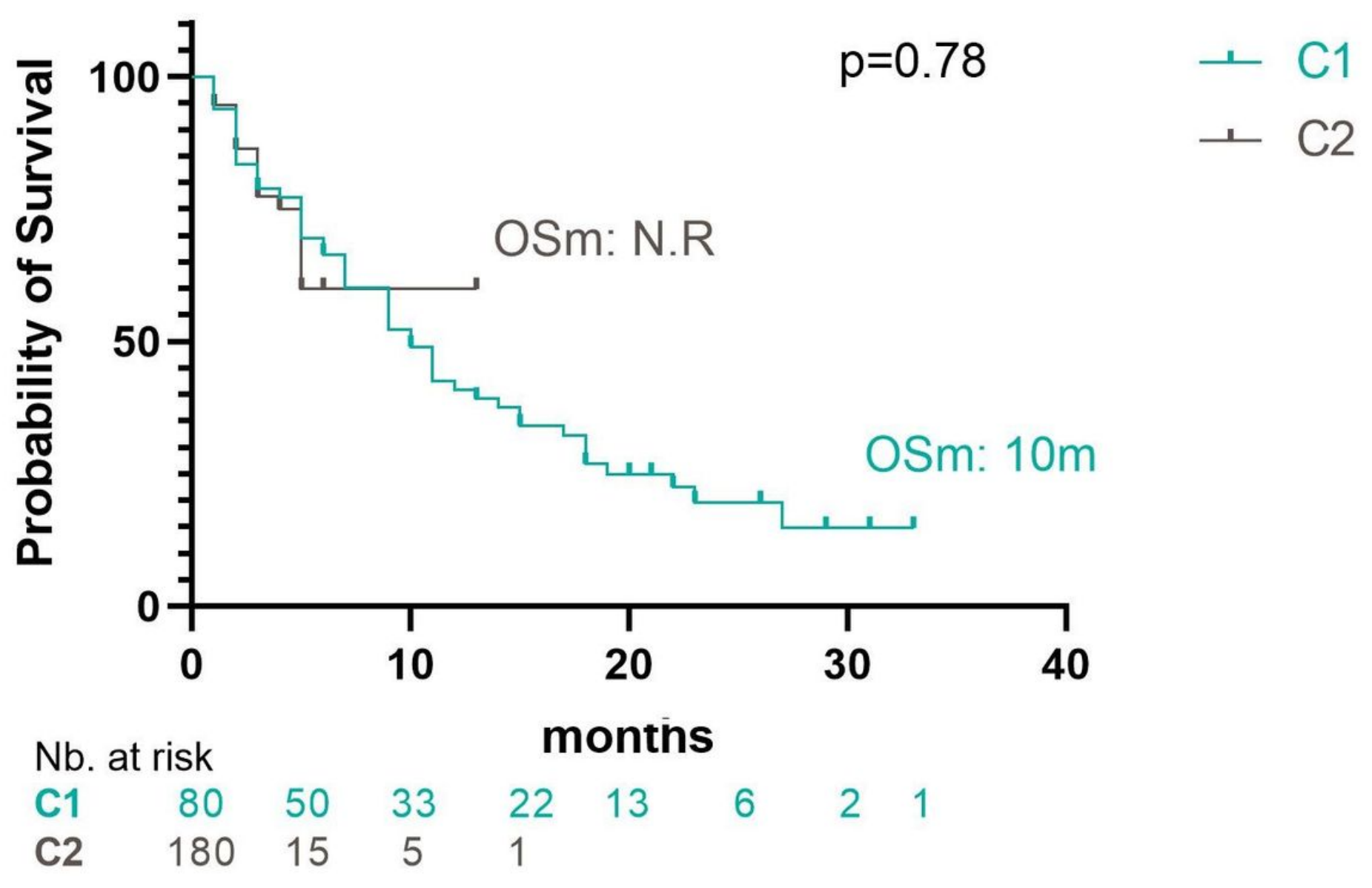


Figure 1

Overall survival at discontinuation of the phase I trial in cohort 1 (C1) and cohort 2 (C2)

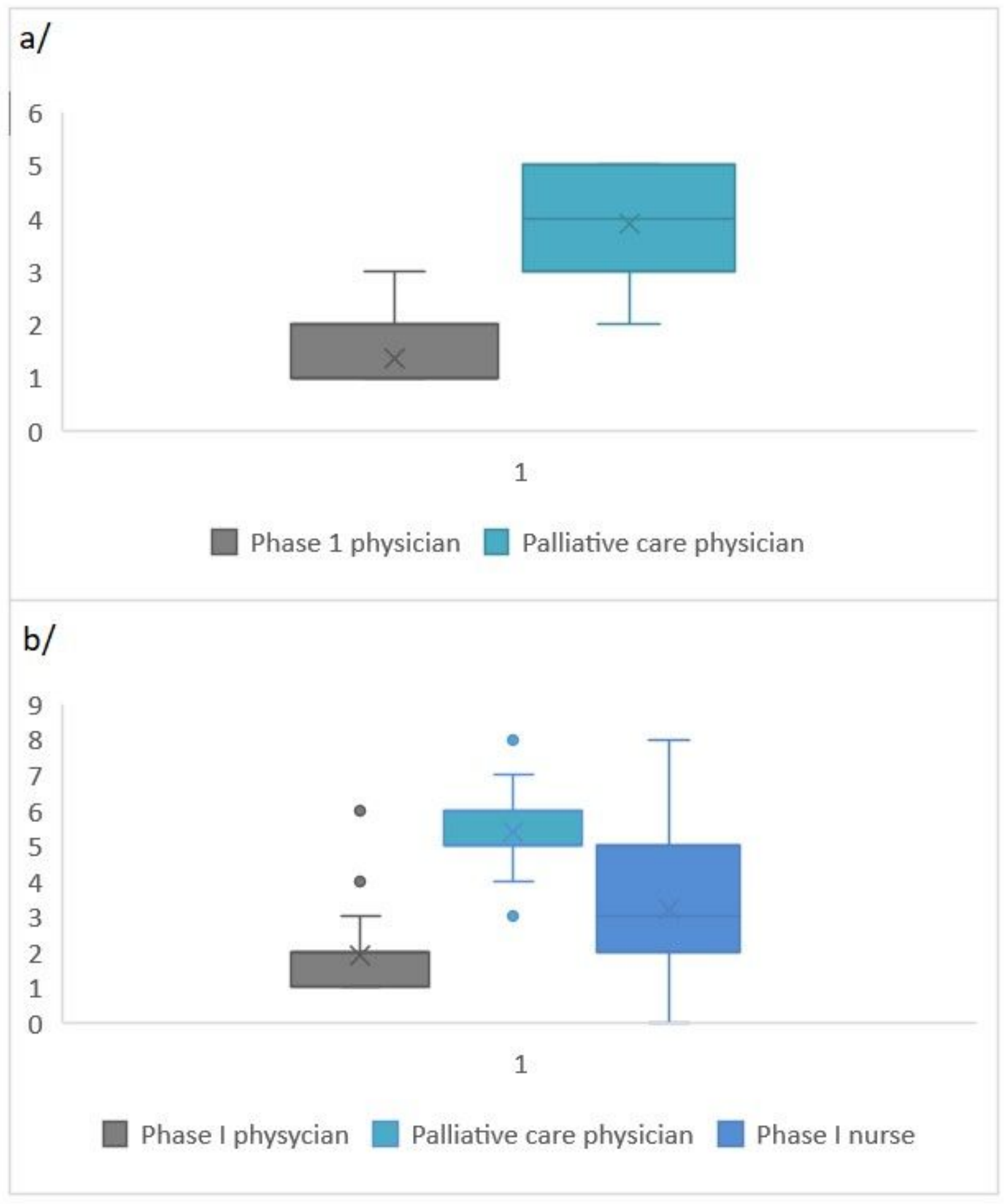

\section{Figure 2}

Assessment of PALLIA 10 in a double bling setting by the phase I physician/palliative care specialist (a) then by the phase I physician/palliative care specialist/ phase I nurse (b) in cohort 2 (C2) 


\section{Supplementary Files}

This is a list of supplementary files associated with this preprint. Click to download.

- Supplementarydata.docx 